\title{
Activization of Scientific and Innovative Sphere for the Region Sustainable Development
}

\author{
Galina Chulkova, Elena Vorobeva, and Oleg Vorobev \\ Smolensk State Agricultural Academy, 10/2, Bolshaya Sovetskaya Str., Smolensk, 214000, Russia
}

\begin{abstract}
The region sustainable development presupposes the creation of conditions ensuring the progressive development to achieve a qualitatively new state of the regional economy. One of the strategic goals of the social and economic development of Smolensk Region is the intellectual property market infrastructure development, the provision of technology transfer and the stimulation of inventive activity in the region. The analysis of the rating of Russian innovative regions showed that according to the most important indicators of innovative activity in industrial production, Smolensk region is in the first half of the all-Russian rating of regions, and the lower activity in research and development is complemented by low indicators of patent activity in Smolensk region in comparison with the average Russian indicator values. In this regard, the issues of the formation and use of the intellectual activity results were identified and priority directions were developed to activate the scientific and innovative sphere of Smolensk region.
\end{abstract}

\section{Introduction}

The Strategy for Social and Economic Development of Smolensk region through to 2030 foresees the region innovative development in the context of the development of branches of the knowledge-intensive economy and the creation of high-tech industries in Smolensk region, the creation of innovative territorial clusters and further changes in the infrastructure of the knowledge-based economy, regional policy to stimulate inventive activity and in the field of intellectual property [1].

In order to achieve this goal, it is required to increase the coefficient of inventive activity in Smolensk region (the number of domestic patent applications for inventions); create conditions for increasing the number of researchers in the region; to intensify the activities of projects aimed at ensuring the availability of additional education programs that reflect the most important trends in the technological development of Russia [2]. Fulfillment of the assigned tasks will positively affect the change in the innovative development level of Smolensk region among innovative regions of the Russian Federation.

The scientific and educational environment in Smolensk region is sufficiently developed. At the same time, it should be noted that there is some kind of difference, on the one hand, in the constantly increasing requirements for the expansion of activities in the scientific field, in the scientific and technical creativity of youth communities, young scientists, qualified specialists, scientific and pedagogical workers, and on the other hand, in a real situation in the considered environment. [3]. In this regard, the inevitability of the 
development of effective levers for massification, motivation, further dissemination of scientific and scientific and technical activities and creativity, aimed at various target audiences at the regional level, arises, thereby providing its sustainable development.

\section{Materials and Methods}

The purpose of this study is to develop measures to activate the scientific and innovative sphere for the sustainable development of Smolensk region. In order to achieve this goal, the following tasks were set and solved: to analyze the innovation rating of Smolensk region; to identify the issues of the formation and use of the intellectual activity results in Smolensk region; to develop priority directions for enhancing the scientific and innovative sphere of Smolensk region.

During this study, the published statistical data of the Federal State Statistics Service, materials of the Association for the Innovation Rating of Russia, materials of the legal and normative-technical documentation of consortium, the Code, information on the activities of autonomous non-profit organizations in Smolensk Region, as well as open information from the Internet were used.

The study used the methods of monographic, abstract-logical, comparative, statistical, economic-mathematical and systems analysis, which allowed the authors to solve the tasks.

\section{Results and Discussion}

The Association of Innovative Regions has developed indicators of innovative development, combined in rating values, reflecting changes in the economy innovative development of each constituent entity of the Russian Federation. The rating formation methodology is based on the approach used by the European Commission to conduct a comparative assessment of the innovative development of EU regions in order to develop and implement innovative policy measures at the regional level (Regional Innovation Scoreboard) [4].

According to the results of 2018, Smolensk region was at 44th place out of the total number of evaluated subjects. This position allowed us to improve the region's performance by one level compared to 2017 and enter the group of "medium innovators" (Table 1).

Table 1. Dynamics of Smolensk region innovative rating.

\begin{tabular}{|c|c|c|c|c|}
\hline Year & Rating & Index & $\begin{array}{c}\text { Percent from the average } \\
\text { national level }\end{array}$ & Group \\
\hline 2014 & 44 & 0.36 & 95.8 & medium innovators \\
\hline 2015 & 50 & 0.35 & 92.8 & medium innovators \\
\hline 2016 & 36 & 0.39 & 101.4 & medium innovators \\
\hline 2017 & 45 & 0.37 & 95.9 & medium innovators \\
\hline 2018 & 44 & 0.38 & 96.5 & medium innovators \\
\hline
\end{tabular}

Drafted by authors according to sources $[4,5]$.

In 2018, the constituent entities of the Russian Federation were ranked considering the main parameters of innovativeness by groups: 29 regions were classified as strong and medium-strong innovators, 24 constituent entities were classified as medium innovators, and 32 participants were classified as medium-weak and weak innovators. The rating leaders are Saint-Petersburg $(0.68 ; 172.9 \%)$, the Republic of Tatarstan $(0.67 ; 169.6 \%)$ and Moscow (0.65; 166.4\%). 
A more detailed analysis of Smolensk region position by the components of the rating for 2016-2018 shall be conducted. The lowest and highest values of the constituent entities of the Russian Federation are shown in parentheses. (Table 2).

Table 2.Smolensk region innovative rating change by components.

\begin{tabular}{|l|c|c|c|}
\hline \multicolumn{1}{|c|}{ Subrating } & $\mathbf{2 0 1 6}$ & $\mathbf{2 0 1 7}$ & $\mathbf{2 0 1 8}$ \\
\hline Scientific research and development & $\begin{array}{c}0.39 \\
(0.07-0.77)\end{array}$ & $\begin{array}{c}0.41 \\
(0.11-0.78)\end{array}$ & $\begin{array}{c}0.40 \\
(0.17-0.76)\end{array}$ \\
\hline Innovative activities of organizations & $\begin{array}{c}0.44 \\
(0.09-0.71)\end{array}$ & $\begin{array}{c}0.40 \\
(0.07-0.69)\end{array}$ & $\begin{array}{c}0.41 \\
(0.08-0.67)\end{array}$ \\
\hline $\begin{array}{l}\text { Social and economic conditions of } \\
\text { innovative activities }\end{array}$ & $\begin{array}{c}0.42 \\
(0.18-0.67)\end{array}$ & $(0.20-0.74)$ & $(0.16-0.67)$ \\
\hline Constituent entity innovative activities & $\begin{array}{c}0.29 \\
(0.00-0.92)\end{array}$ & $\begin{array}{c}0.20 \\
(0.00-0.84)\end{array}$ & $(0.00-0.85)$ \\
\hline
\end{tabular}

Drafted by authors according to sources $[1,6]$.

The highest degree of scientific research and development is in Moscow (0.76), SaintPetersburg (0.74) and Tomsk region (0.65).

The Republic of Tatarstan (0.67), Nizhny Novgorod region (0.65), city of SaintPetersburg (0.60), Tomsk region (0.58), Moscow region (0.58) are favorites in terms of innovation.

Cities of Moscow (0.67), Saint-Petersburg (0.65) and subjects of Kaluga region (0.66), Ulyanovsk region (0.63) have the most developed social and economic conditions for innovation.

The highest innovative activity is in Novosibirsk region (0.65), Tomsk region (0.85), Republic of Tatarstan (0.81), Kaluga region (0.76), city of Saint-Petersburg (0.72), Moscow region (0.70), Samara region (0.68), the Republic of Bashkortostan (0.68).

The analysis of Smolensk region innovation rating components led to see that the region was at 59th position (0.40) in research and development, which was a decrease of 7 steps in relation to the previous year (Fig. 1).

The insufficiently high position of Smolensk region is associated with a low indicator of student number in higher education institutions (228 people per 10 thousand people). From year to year, the number of students decreases, and compared to 2011, it has decreased by half (from 442 to 228). The number of research scientists per million of the region's population has also decreased (from 58 to 54).

At the same time, the costs of an internal nature associated with research and development have a steady tendency to a constant increase over the previous seven years as a percentage of the gross regional product (from 0.48 to 0.57 ).

Scientific studies and developments reflect data on patent activity, its indicators have an insignificant regional level.

Smolensk region has a positive trend in main parameters of investment and innovative development, however, there are obstacles in the form of unstable parameters associated with the results of intellectual activity in its organization and their application. 


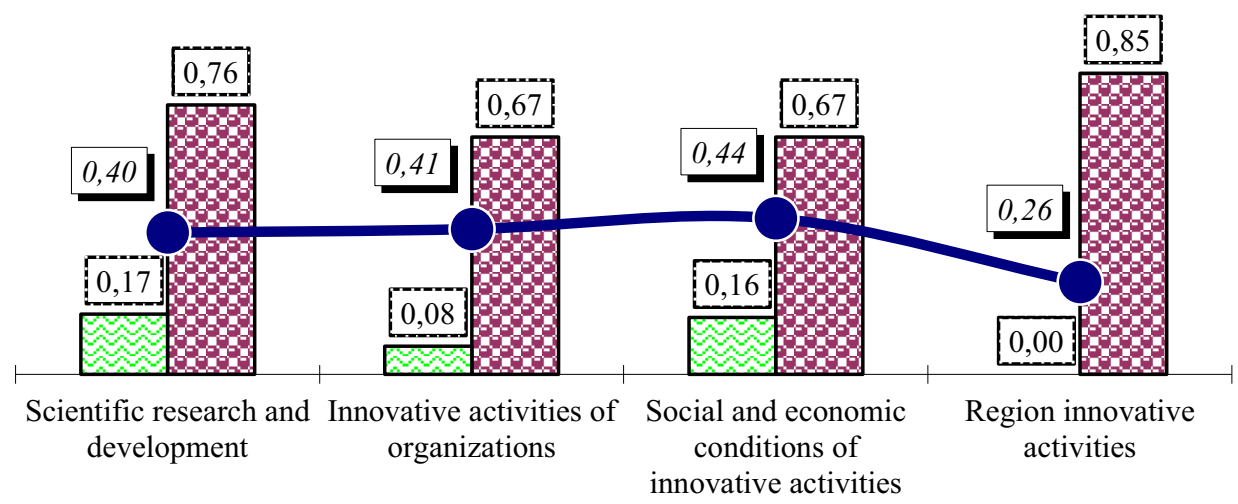

Maximum

Mimimum

-0Smolensk region rating

Fig.1. Smolensk region position in innovative rating components in 2018. Drafted by authors according to sources $[1,6]$.

In order to promote the development of innovations and patent activity in the subject territory of Smolensk region, functional steps have been taken recently.

In 2016, at the direction of the Governor of Smolensk Region, with the support of the Ministry of Economic Development of the Russian Federation, an autonomous non-profit organization "Center for Cluster Development of Smolensk Region" was created. The Center for Cluster Development provides various types of services to small and mediumsized businesses, including in the innovation sphere, which contributes to the further development of clusters on the territory of the region.

The Entrepreneurship Support Center works with small and medium business, as well as with individuals interested in doing business. The Entrepreneurship Support Center assists in conducting patent research to determine the current patent situation, for example, exploring the possibility of free use of an object, equipment or products without the risk of infringement of previously existing patents; determines the directions and levels of various options for activities (innovation, production, commercialization) operating in the market under study; considers potential participants and competitors to identify and select objects for licensing and patenting [7].

In Smolensk region, the activities of the Center for Youth Innovative Creativity YAVIR are provided. The Center was established on the basis of FabLab model in order to provide access to small and medium businesses in differentiated areas and the implementation of projects for school children and students. The Center for Youth Innovative Creativity is equipped with equipment that allows solving issues of commercialization and engineering, prototyping and prototyping, engaging in technical creativity, as well as developing in the field of biotechnology.

In order to stimulate research work in the field of fundamental and applied science, ensure the high level of organization of scientific research in Smolensk region, a number of scientific projects are carried out annually, which are aimed at supporting individual scientists carrying out scientific research and the effective work of creative teams, including: project competitions fundamental scientific research, scientific and practical conferences, the NAUKA 0+ science festival, the regional stage of the all-Russian program UMNIK [8]. 
The Smolensk regional branch of the all-Russian public organization "Russian Union of Young Scientists" makes a significant contribution to the formation of science on the territory of the subject. Scientific research is carried out by the team of the organization in such areas as ecology and geography, technical sciences, medicine, information technologies.

Smolensk region needs an Innovation and Technology Support Center, which is an innovative infrastructure element. In most constituent entities of the Russian Federation, such centers are already functioning within the framework of the project of the World Organization of Technology and Innovation Support Centers (TISCs) [9]. The primary areas of their activity are associated with participation in the organization of training seminars, promotion of knowledge in the field of intellectual property, providing inventors and other involved persons with remote access to patent and technological information (abstracts and full-text databases) and the provision of related services (consulting on search, filing applications, legislation in the field of intellectual property, etc.).

The further formation of Smolensk region innovative potential requires the expansion of innovation infrastructure elements aimed at involving young people in inventive and innovative activities through the Quantorium children's technology parks. In addition, in terms of the development of inventive activity of young people, it is advisable to provide students with basic knowledge about working with intellectual property.

\section{Conclusions}

1. The conducted analysis allowed to identify the following issues: the discrepancy between the constantly increasing requirements for improving activities in the field of science and technological creativity of young people, qualified specialists, scientific and pedagogical staff and the realistic state of the presented sphere; low patent activity; low rates of use of the results of intellectual activity; the lack of a technology and innovation support center in the region as an important element of the innovation infrastructure; lack of components of the innovation infrastructure focused on involving young people in inventive and innovative activity

2. Based on the identified issues, the priority directions were developed to activate the scientific and innovative sphere of Smolensk region: organization of the Center for Technology and Innovation Support in Smolensk region; conducting training programs in the field of intellectual property and the development of innovative activities; informative and consulting assistance to business by organizations of the infrastructure for supporting small and medium-sized businesses in matters of legal protection of the results of intellectual activity, the implementation of patent research, as well as providing information on the current mechanisms of state support for innovation; creation of a children's technopark Quantorium within the framework of the federal project "Success of every child" with the aim of teaching children in the areas of bio-quantum, cosmo-quantum, industrial-design-quantum, industrial-robot-quantum, high-tech, IT-quantum; holding competitive and congress events aimed at supporting scientific and innovative activities in the region, including holding youth competitions and olympiads in the field of intellectual property.

\section{References}

1. Strategy for social and economic development of Smolensk region through to 2030, http://docs.cntd.ru/

2. O.V. Lazko, Major Aspects of economics and agricultural business, 188 (2017) 
3. E.S. Vorobieva, P.A. Grigoriev, Modern digital technologies in agro-industrial complex. Collection of international scientific conference materials, 64 (2020)

4. Association of innovative regions of Russia, https://i-regions.org

5. A.N. Alekseev et al, Prospects of Russian industry economy digitalization: peculiarities and conditions (2018)

6. Federal state statistics service of the Russian Federation, https://rosstat.gov.ru

7. A. A. Uskov et al, Territory development: past, present, future (2020)

8. N.Z. Goncharova, S.E. Terentyev, E.S. Vorobeva, O.B. Tarasova, International conference on policicies and economics measures for agricultural development (AgroDevEco 2020). Advances in economics, business and management research, 114 (2020)

9. O. Patlasov, Y. Zharov, Journal of advanced research in law and economics, 1428 (2018) 